\title{
INTEGRATION OF PRE-SIMULATION AND SENSORLESS MONITORING FOR SMART MOULD MACHINING
}

\author{
Kim, S.-J. \\ Department of Mechanical Engineering, Gyeongsang National University, Jinju 52818, \\ Republic of Korea \\ E-Mail: sujinkim@gnu.ac.kr
}

\begin{abstract}
A smart mould machining system, which detects machining status and controls the $\mathrm{CNC}$ through presimulation and real-time data, was developed. Pre-simulation predicts cutting forces, and inserts the best feed rate and virtual load on each line of the NC data. The active feed rate reduced machining by up to $36 \%$, without increasing the maximum cutting forces. The actual cutting load was computed from spindle load data and a friction load compensation algorithm. Collision and tool wear were detected by comparing the actual and virtual load, with the time synchronised by using tool position data. The system machined an automotive grill mould cavity for 34 hours without the supervision of a worker, because pre-simulation had stabilized the milling process and monitoring would have stopped the process if the actual load was different to the virtual load. Pre-simulation has been verified by thousands of mould makers and integrated with sensorless monitoring in an open CNC.

(Received in November 2015, accepted in April 2016. This paper was with the author 1 month for 1 revision.)
\end{abstract}

Key Words: Smart Mould Machining, Pre-Simulation, Feed Rate Control, Sensorless Monitoring, Tool Wear, Open CNC

\section{INTRODUCTION}

A mould is a special shaped cavity used to produce large quantities of the same product. A plastic part is designed by $\mathrm{CAD}$ and modified by the numerical simulation of injection moulding process. A mould-base type is selected and final cavity and core are designed [1]. Manufacturing companies develop a mould and produce millions of parts from it using a plastic injection machine. Mass production lines repeat the machining of lots of the same parts through a single NC program, but mould machining is always the first process when using a new workpiece, cutting tools or NC program for each design. New NC data for complex moulds, which are prone to collision accidents, tool wear and tool breakages, have their cutting conditions set based on the worst case geometry. Though the machine tool stops if the feed driving or spindle motor load is larger than the fixed maximum value, this may occur after all the teeth of the tool have already been broken or a collision between the spindle and workpiece has happened. The operator has to monitor the NC machine during the operation and push the stop button in cases of abnormal cutting states, even though it is a fully automated machine tool. The first system required in the mould industry is practical machining process monitoring. This allows the machine to be observed without an operator after the stock is fixed on the table and cutting tools are prepared in the tool changer magazine.

A significant amount of research has been dedicated to the task of cutting tool monitoring [2]. A direct measurement of tool wear on machine tools using laser displacement sensor is presented [3]. A frequent approach used in laboratories is to attach vibration, acoustic emission and dynamometer sensors to the machine and then monitor the signals obtained. The measurement of cutting force is commonly taken using a table-mounted dynamometer, which is an essential tool for laboratory based experimental work [4-6]. Flank wear and tooth breakage can be monitored from acceleration and vibration signals during milling $[7,8]$. The practical approach applied in machine shops is to monitor spindle or feed drive current without using expensive additional sensors. The cutting forces in the $\mathrm{x}, \mathrm{y}$ and $\mathrm{z}$ axes, which 
were measured indirectly from the current of the feed-drive servo motors, were used for cutting force regulation and tool monitoring in slow face milling [9-12]. The monitoring of spindle load or current is a well-established approach to tool condition monitoring using adaptive control [11-14]. Spindle current monitoring was utilized to develop an adaptive control for machine tools when workpiece geometry is unknown [13-15]. A time series autoregressive model proposed a method for monitoring tool breakage [16].

The previous adaptive control or time series autoregressive model is useful for drilling or simple milling processes in mass production, where the same machining pattern is repeated. However, it is insufficient when it comes to new NC data of complex mould geometries and changing cutting conditions. Therefore, a robust monitoring model, which separates the measured load of an abnormal cutting state from the general load change induced by an increase in cut depth or changes in cutting conditions, needs to be applied in mould machining, where the cutting geometry and conditions change often during the process.

In this paper, a smart mould machining system, which recognises cutting status and adjusts to better cutting conditions using pre-simulation data and real-time measured signals, has been developed. Pre-simulation estimates machining loads by assuming an ideal tool, and inserts the best feed rates and virtual loads on every line of output NC data. Real-time monitoring recognises collision and tool wear by comparing actual and virtual load data.

The reference virtual load is estimated by pre-simulation of $\mathrm{NC}$ machining developed using Visual $\mathrm{C}++$ and the OpenGL library. Instantaneous cutting forces and average powers are computed from the specific cutting energy and intersection of tool and workpiece [17-24]. The active feed rate is inserted in NC data to reduce machining time while the instantaneous maximum cutting force is below the limit. Instantaneous cutting forces are compared with forces measured by the tool dynamometer, and virtual cutting load is compared with the actual load gathered from spindle load data. The developed smart mould machining system has been verified by mould makers, and integrated in an open CNC easily because presimulation and sensorless monitoring software does not require additional sensors or instruments.

\section{PRE-SIMULATION}

\subsection{Machining simulation and collision avoidance}

The simulation system reads the NC data generated by commercial CAM software. It recognizes the diameter and corner radius of the tool from NC code comments and inputs the starting workpiece geometry. The stock model is expressed by z-buffer, which is useful for 3axis cutting simulations $[17,18]$. Pre-simulation verifies the $\mathrm{NC}$ data and protects machine tools from collisions between spindle heads, holders, fixtures, workpieces and cutting tools. The safe and shortest tool-setting algorithm using a safe space was proposed and applied in NC machining [19]. The safe space is the volume in a tool coordinate system that does not interfere with the workpiece, and the holder located in the safe space never collides with the workpiece. Collisions at rapid motion between the safe space and workpiece are demonstrated in pre-simulation. If a rapid motion collision is predicted, the rapid motion height is increased to a safe height. If the original rapid height is too high, resulting in a loss of rapid motion time, the height is decreased to the lowest safe height. The tool holder assembled in the safe space does not collide with the workpiece.

\subsection{Cutting force model and experiment}

Cutting force is computed using chip geometry, which is the overlap of the workpiece and tool moving along tool paths [20]. Pre-simulation calculates the instantaneous cutting forces using chip removal geometries. Chip removal geometries are divided into small pieces on a 
cylindrical coordinate to estimate element cutting forces more accurately, as shown in Fig. 1. The uncut chip thickness $t_{c}$, i.e., the thickness of the material removed by a flute, at any location on the cutter, can be determined using Eq. (1), where $f_{t}$ is the feed per tooth vector and $n_{s}$ is the unit normal vector of cutter surface at the angular position $\theta$ and axial height $z$ $[21,22]$.

$$
t_{c}(\theta, z)=f_{t} \cdot n_{s}(\theta, z)
$$

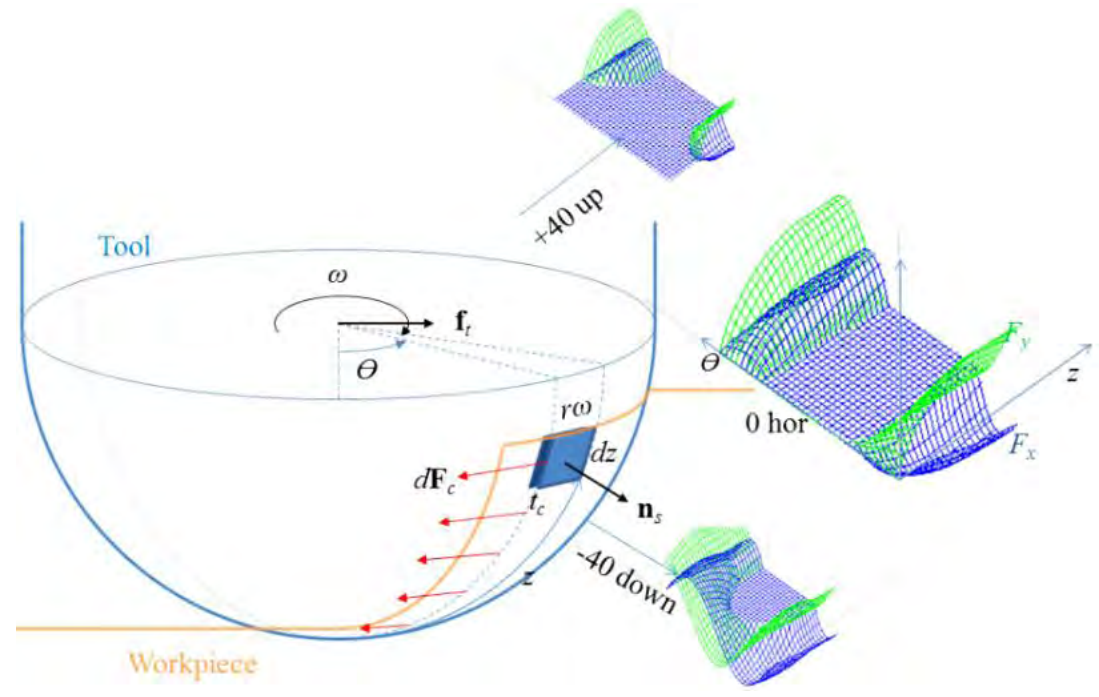

Figure 1: Element cutting forces on a tool.

The element cutting forces on a tooth are computed from the chip area and specific cutting energy, which also changes with the uncut chip thickness. The relationship between a specific cutting energy and uncut chip thickness, as proposed by Sabberwal, is used to consider the size effect [21-26]. The specific cutting energy is a function of the uncut chip thickness and empirical constants $K_{c}$ and $p$, which are dependent on the tool and material. The tangential and radial components of the element cutting forces $d F_{c}$ are computed from the specific cutting energy, chip thickness and chip width $d z$, as shown in Eq. (2).

$$
\left[\begin{array}{l}
d F_{c T} \\
d F_{c R}
\end{array}\right]=\left[\begin{array}{l}
K_{c T}\left(t_{c}\right)^{p_{T}} \\
K_{c R}\left(t_{c}\right)^{p_{R}}
\end{array}\right] d z
$$

Fig. 1 shows the element cutting forces when a tool moves in a direction that is -40 degrees downward or horizontal or +40 degrees upward. The instantaneous cutting force $F_{c}$ is computed by adding the element cutting forces of tooth $N$ along the axial depth of the cut $d_{\mathrm{a}}$, as shown in Eq. (3) [21-25].

$$
\left[\begin{array}{c}
F_{c X}(\theta) \\
F_{c Y}(\theta)
\end{array}\right]=\int_{d_{0}}^{d_{a}} \sum_{1}^{n}\left[\begin{array}{cc}
\cos (\theta) & -\sin (\theta) \\
\sin (\theta) & \cos (\theta)
\end{array}\right]\left[\begin{array}{l}
K_{c T}\left(t_{c}\right)^{p_{T}} \\
K_{c R}\left(t_{c}\right)^{p_{R}}
\end{array}\right] d z
$$

The instantaneous cutting force computation model was verified by comparing with experimental forces measured using a table-mounted tool dynamometer. The cutting tool is a $10-\mathrm{mm}$-diameter ball end mill and the workpiece is SM45C carbon steel. The spindle speed is $1000 \mathrm{rpm}$ and feed rate is $200 \mathrm{~mm} / \mathrm{min}$. Fig. 2 (top) shows the predicted instantaneous cutting forces, and Fig. 2 (bottom) shows the actual instantaneous cutting force measured by the tool dynamometer when the axial cut depth is $5 \mathrm{~mm}$ and radial cut depth is changed from $5 \mathrm{~mm}$ to $1 \mathrm{~mm}$. The predicted cutting force is similar to the experimental one.

\subsection{Feed rate pre-control to reduce machining time}

A cutting tool is deflected and vibrated by the maximum instantaneous cutting force. Presimulation controls the feed rate, shortening the machining time, while the maximum forces 
are below the limits [21]. This was evaluated by cutting a $50 \mathrm{~mm} \times 50 \mathrm{~mm} \times 50 \mathrm{~mm}$ piece of SM45C carbon steel with a $10-\mathrm{mm}$-diameter flat end mill. The machining time is 3 min $40 \mathrm{~s}$ when using the original $\mathrm{NC}$ data with a constant feed rate. The machining time is $2 \min 20 \mathrm{~s}$ when the optimized $\mathrm{NC}$ data with a controlled feed rate is used. Machining time savings of approximately $36 \%$ are achieved by using the pre-controlled feed rate, while the maximum cutting force is not increased, as shown in Fig. 3.
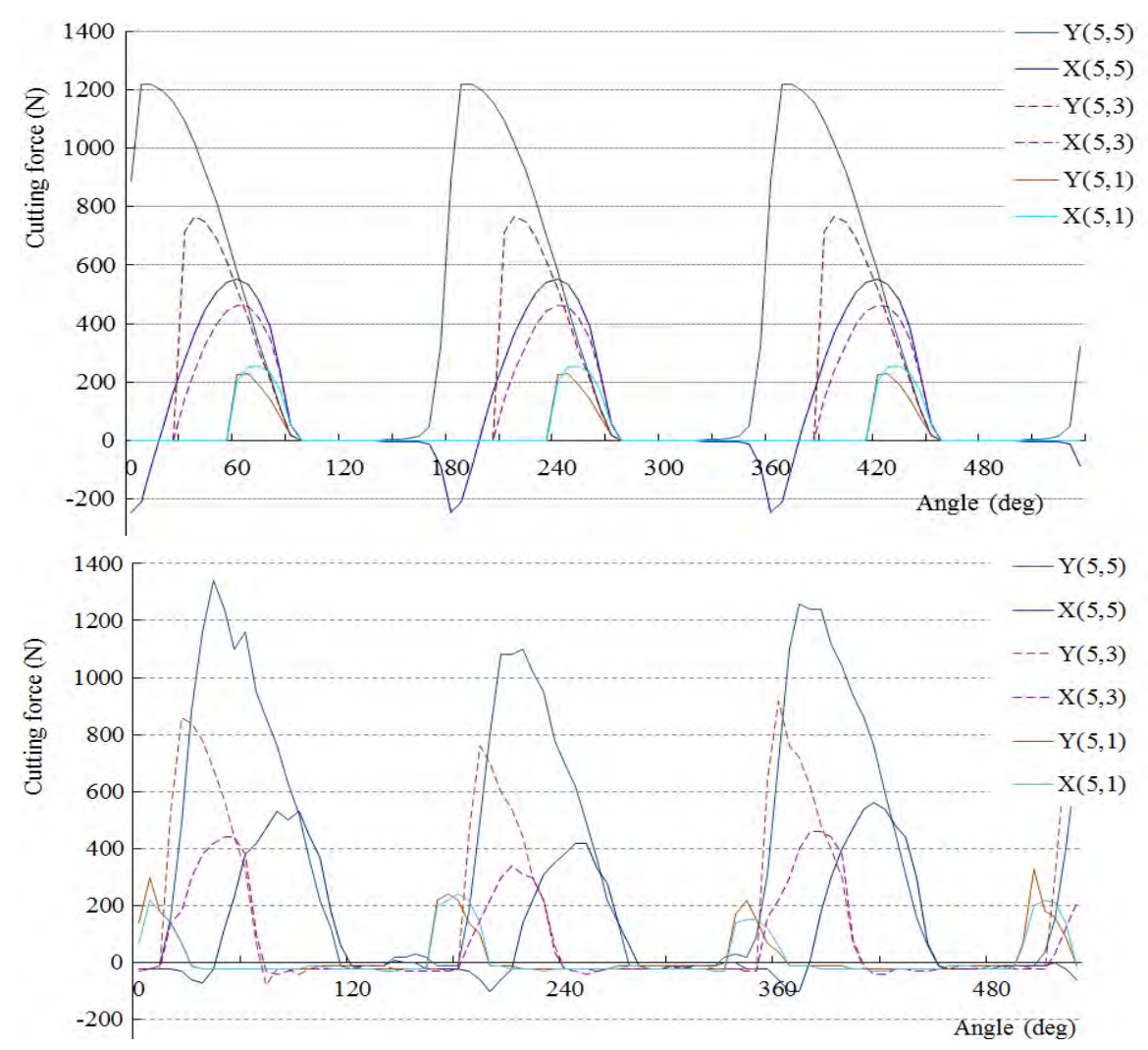

Figure 2: Predicted (top) and measured (bottom) instantaneous cutting forces.
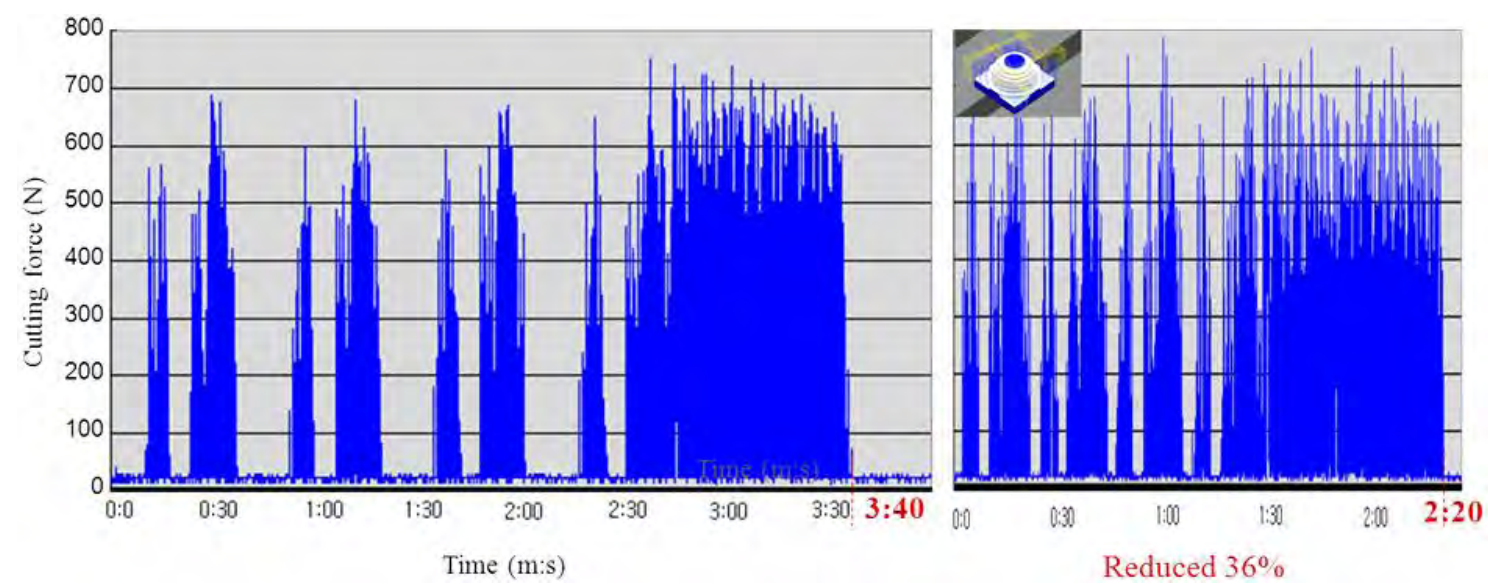

Figure 3: Pre-control feed rate to save machining time.

Controlling feed rate based on chip geometry can achieve process stability when milling complex moulds [25]. The machining conditions of NC data, generated by CAD software are single, although the cutting depth and direction change at each line of the tool path. The simulation system knows the chip geometry of every rotation angle of the teeth. It regulates cutting conditions by using the cutting force required to remove the chip geometry, as well as the database, which takes into account the cutting tools, workpiece materials and machine tool 
specifications, as shown in Fig. 4. The regulated feed rate in NC data allows for safe and fast machining. The pre-simulation system was developed through 10 -year collaboration between the author and a company using $\mathrm{C}++$ language and the OpenGL library. It was commercialized successfully and thousands of mould makers are using it to pre-control cutting conditions before real machining [27]. The virtual load computation algorithm and sensorless monitoring system were developed for this research and integrated with the presimulation in an open CNC.

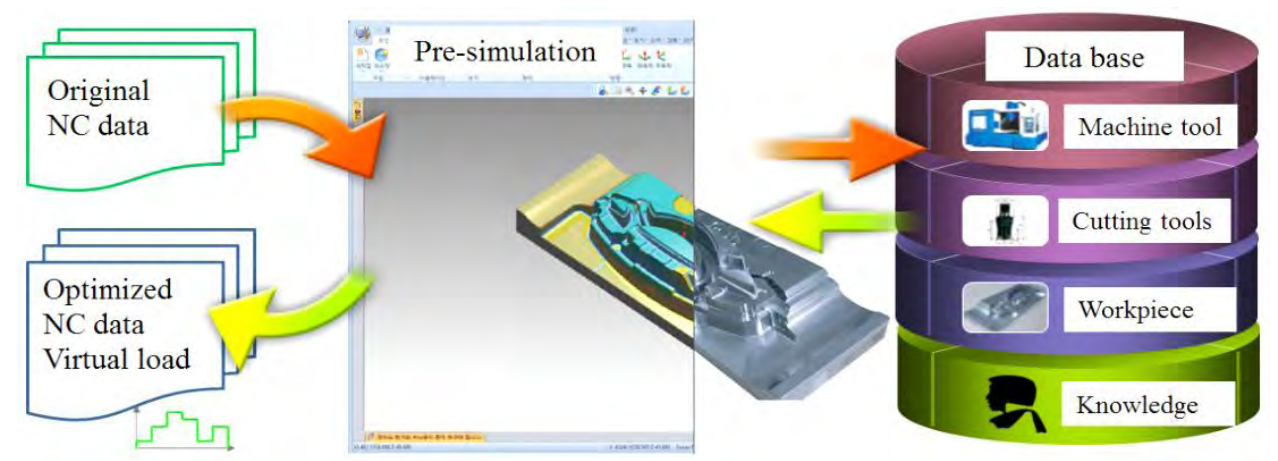

Figure 4: Pre-simulation software.

\subsection{Virtual load for monitoring}

A virtual load calculation function was developed for this research and used at the sensorless monitoring step. The pre-simulation virtual load is the power required to cut the workpiece under various mould machining conditions. It does not include the power required to rotate the spindle against static friction or to accelerate spindle speed.

The cutting power $P_{c}$ is computed by adding all element torques computed using the specific cutting energy and chip volume, as shown in Eq. (4). The experimental constants $K_{c T}$ and $p_{T}$ of the specific cutting energy change with tool wear. They are independent of the cutting depth and machining conditions, which are computed by simulation. Robust monitoring, which divides the tool wear and chip removal volume, is possible, if simulation and monitoring are integrated into a system.

$$
P_{c}=\int_{0}^{2 \pi} \int_{d_{0}}^{d_{a}} \sum_{1}^{n} K_{c T}\left(t_{c}\right)^{p_{T}} d z r \omega d \theta
$$

The spindle load data of the controller represent the relative units computed by dividing the current spindle power by the maximum power of the machine. The virtual cutting load $P_{V}$ is computed by changing the unit of cutting power with an empirical constant $C_{V}$, which is dependent on the machine tool, as shown in Eq. (5).

$$
P_{V}=C_{V} P_{c}
$$

The pre-simulation system inputs the workpiece size, roughing tool and tool path. It simulates machining and outputs the machined stock and NC data including pre-control cutting conditions and virtual cutting load information. The stock generated from the previous simulation is input into the next step. The estimated virtual load is expressed by the special code "(L number)" inserted at the end of every NC code block. The tool position and virtual load data of each line are the references for the sensorless monitoring step.

\section{SENSORLESS MONITORING}

\subsection{Sensorless monitoring and control by Ethernet}

The controllers open control parameters to be accessed by Ethernet communication. This study obtains not only spindle load but also actual spindle speed, feed rate and NC code block 
every $0.2 \mathrm{~s}$ using a Fanuc $18 \mathrm{i}$ series Ethernet connection. The communication program was developed by Visual Studio and Fanuc Focas library [27]. It can access almost all of the information stored inside the $\mathrm{CNC}$, to detect real-time state and control machining conditions. The selected practical real-time data is the spindle load including actual cutting load. A sensorless monitoring and control program was developed that obtains operating condition data of the CNC by local Ethernet, and recognises unpredicted collision or tool wear by comparing with pre-simulation data. The system is able to be integrated in the Fanuc 30i series, using the Windows operating system at a human-machine interface, because real-time monitoring and control does not use additional sensors or instruments.

\subsection{Acceleration and friction load during air cutting}

The spindle load data includes not only the actual cutting load but also the friction load rotating axis against the friction torque and acceleration load to accelerate angular speed. The characteristics of the acceleration load and friction load disturbance are observed in the air cut experiment, and the compensation method is designed.

The acceleration load is the power used over a short time to accelerate and decelerate the angular speed to the input value. The servo motor uses a lot of power to accelerate and decelerate spindle speed due to the large angular moment of inertia. Spindle acceleration load is measured when the spindle is turned on and accelerated to $4500 \mathrm{rpm}$, as shown in Fig. 5 (top). The spindle speed arrives at the command value after $3 \mathrm{~s}$ and the load drops down to the friction load level rapidly. The initial friction load is computed by averaging data measured $3 \mathrm{~s}$ after the spindle speed is changed.
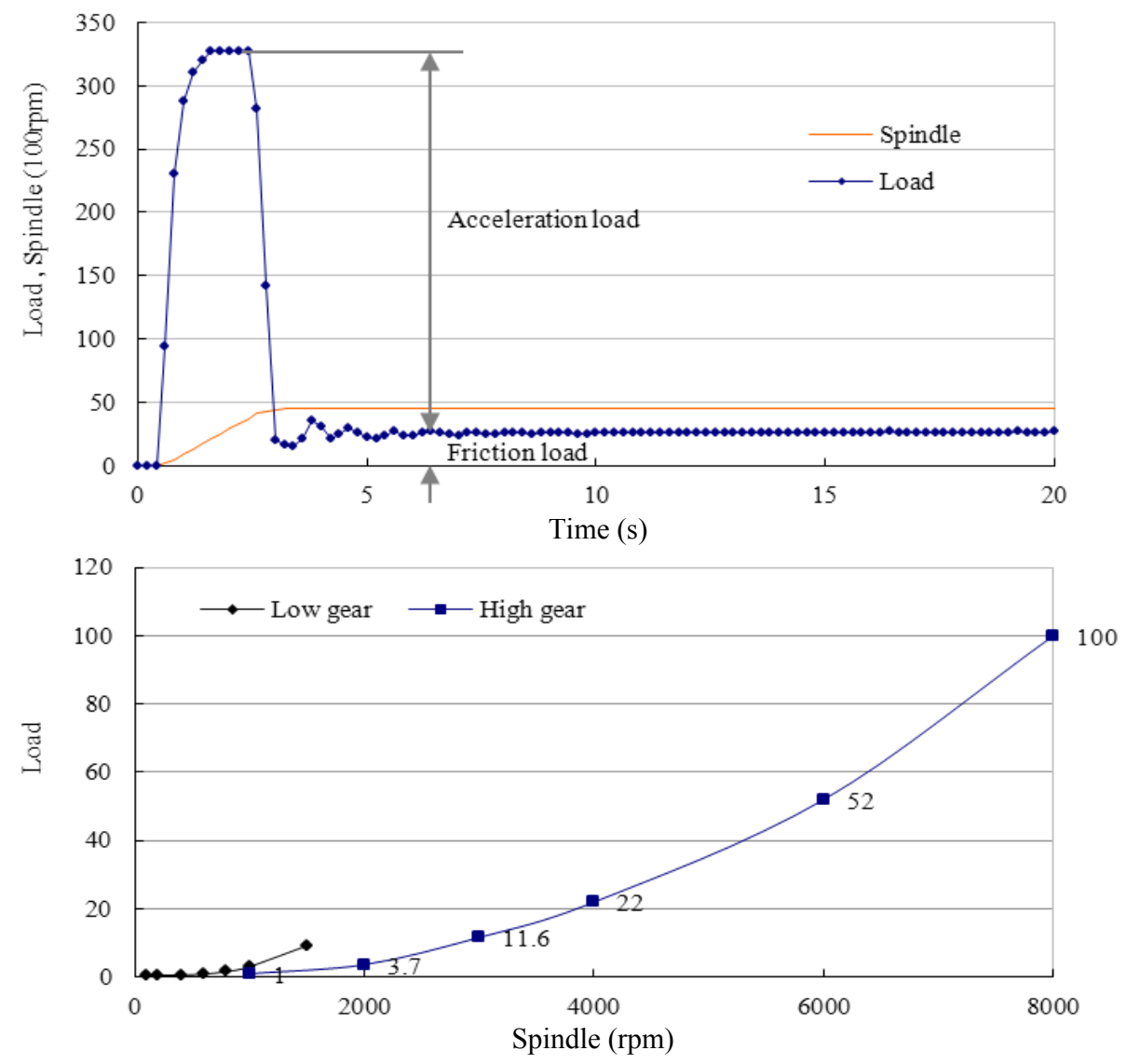

Figure 5: Spindle acceleration load (top) and friction load (bottom).

In this study, the system uses both spindle load and speed to decide if the sudden load increase is caused by a change in spindle speed or collision accident. Because the acceleration 
load is too large to be accurately compensated, the state is divided into a changing spindle state and constant spindle state. After the spindle speed changes, the system quickly looks for the initial friction load and initializes related parameters.

The minimum power required to rotate a spindle at a constant angular speed is the friction load. It is measured while the spindle rotates in air without cutting a workpiece. It is dependent on the gear ratio and quadratic function of spindle speed, as shown in Fig. 5 (bottom). The friction load is 3.7 at $2000 \mathrm{rpm}$ and increases to 100 at $8000 \mathrm{rpm}$. The signal noise of friction load is 0.2 at $2000 \mathrm{rpm}$ and increases to 1.0 at $8000 \mathrm{rpm}$. The monitoring system should reset the friction load level if the spindle changes. It was also observed that the friction load is 103 at $20 \mathrm{~s}$ and decreases slowly to 98 at $3 \mathrm{~min}$, even though the spindle speed is constant at $8000 \mathrm{rpm}$ during an air cut. The monitoring system should update the friction load continuously at a constant spindle speed. After spindle changes, the monitoring system resets the friction load at the initial air cut and updates the following minimum loads continuously until the end of the machining step.

\subsection{Actual cutting load}

The actual cutting load is the power used to cut the material. The spindle load data $P_{s}$ includes not only the actual cutting load $P_{A}$, but also the friction load and acceleration load, as shown in Eq. (5). The friction load is related to the viscosity friction constant $C_{v}$, Coulomb friction constant $C_{\mu}$ and angular velocity $\omega$. The acceleration load is related to the inertia constant $C_{I}$ and angular acceleration $[11,18]$.

$$
P_{S}=P_{A}+C_{v} \omega^{2}+C_{\mu} \omega+C_{I} \frac{d \omega}{d t} \omega
$$
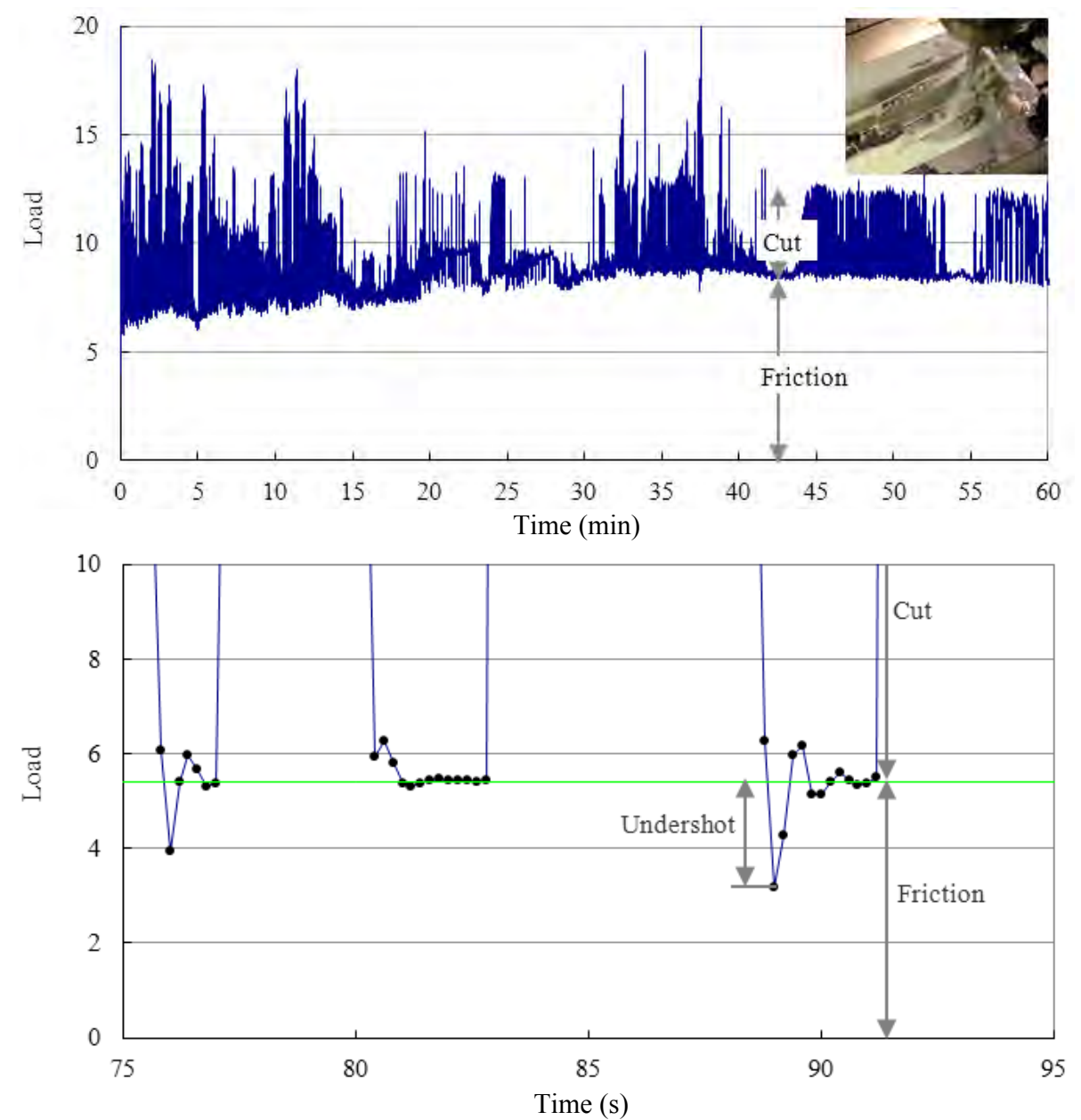

Figure 6: Slow friction load change (top) and undershot noise (bottom). 
The actual cutting load and friction load were observed at the corner pencil machining step for an automobile bumper mould. The tool is a 12-mm-diameter ball end mill and the spindle speed is $2600 \mathrm{rpm}$. As shown in Fig. 6 (top), the lower value of the graph is the friction load and the higher value minus the lower value is the cutting load. The cutting load changes quickly and the friction load changes slowly during the process. The local minima of load data are pushed in a buffer and the minimum value from the previous time is selected as the friction load. The actual cutting load is computed from the real-time spindle load minus the friction load.

Undershot noise is observed when a 50-mm-diameter cutter exits from a large cutting depth. The cutting conditions were spindle speed of $1800 \mathrm{rpm}$, feed rate of $3000 \mathrm{~mm} / \mathrm{min}$, and cut depth of $0.5 \mathrm{~mm}$. The magnitude of the undershot noise was approximately 3 and the duration was $0.6 \mathrm{~s}$, as shown in Fig. 6 (bottom). This induces friction load error, which is a critical problem when it comes to monitoring tool wear. This system selects a middle value from the load data $1.2 \mathrm{~s}$ after the large drop to compensate for the undershot noise of the friction load.

\subsection{Tool wear detection experiment}

Conventional tool wear detection algorithms that compare current spindle loads with an initial value can't be used in mould machining, because changing the cut depth and machining conditions affects spindle loads more than tool wear. In this study, the pre-simulation step records these predictable causes of cutting load change in the NC data block, and the monitoring system detects tool wear by comparing the actual load to the virtual load. The actual load $P_{A}$ is divided by the virtual load $P_{V}$ at current time $n$, and passed actual loads are divided by virtual loads of passed time from 1 to $n-1$, as shown in Eq. (6). If the difference between them is greater than the maximum wear the system stops the controller and sends an alarm message.

$$
\frac{P_{A n}}{P_{V n}}-\frac{\sum_{i=1}^{n-1} P_{A i}}{\sum_{i=1}^{n-1} P_{V i}}>w_{\max }
$$

The tool wear detection algorithm using pre-simulated NC data was tested at the roughing step in a mould machining process of a company. The cutter diameter is $50 \mathrm{~mm}$ and the radius of the three circle-shaped inserts is $6 \mathrm{~mm}$. The pre-simulation system inputs a spindle speed of $1300 \mathrm{rpm}$ and pre-controls the feed rate from $240 \mathrm{~mm} / \mathrm{min}$ to $6000 \mathrm{~mm} / \mathrm{min}$ to reduce machining time, while the instantaneous maximum cutting forces are below the limit. Presimulation inserts virtual load data in the NC file and the monitoring step uses it to separate tool wear load from a general increase in cutting depth. Fig. 7 shows the actual load and virtual load from beginning to end. The actual and virtual load is the same at the beginning for the recycled insert, as shown in Fig. 7 (top). The pattern of the actual load is different to the virtual load from $40 \mathrm{~min}$, and the monitoring system stopped the machining process at $69 \mathrm{~min}$ because the ratio of the actual load to virtual load at the current time is 0.2 larger than the ratio of the passed data, as shown in Fig. 7 (bottom). The three inserts at the beginning and end of machining are shown in Fig. 7. This experiment proved that the real-time monitoring system detects tool insert wear in a real mould machining process.

\section{INTEGRATION MOULD MACHINING SYSTEM IN AN OPEN CNC}

\subsection{Pre-simulation mould machining results}

A smart mould machining system, which pre-controls cutting conditions and monitors the process using pre-simulation data, was developed. The pre-simulation system estimates instantaneous maximum cutting forces and pre-control feed rate by inserting the best feed 
commands into $\mathrm{NC}$ data to save time. It also inserts the virtual load computed by averaging the cutting torque on every line of output NC data.
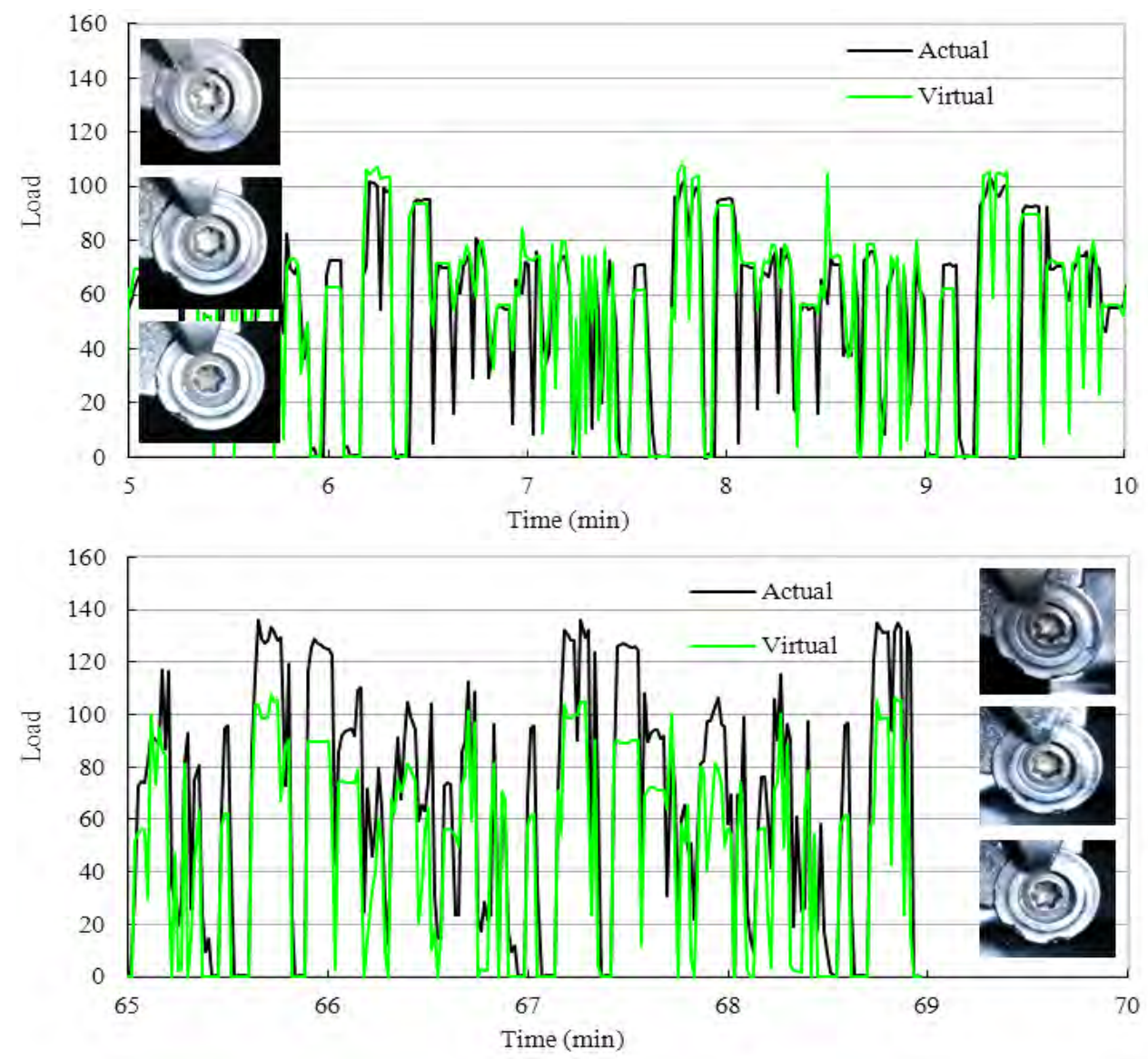

Figure 7: Tool wear detection experiment.

A plastic injection mould of an automobile front grill was machined using a smart mould machining system. The workpiece size is $980 \mathrm{~mm} \times 440 \mathrm{~mm} \times 210 \mathrm{~mm}$ and the material is KP4 die steel. The diameters of the 24 tools used in this machining process range from $50 \mathrm{~mm}$ to $2 \mathrm{~mm}$. The pre-simulation step controlled the cutting conditions, which are inserted into $\mathrm{NC}$ data with the virtual cutting load.

During the roughing step, a large volume is removed from the rectangular stock using a cutter with a $50-\mathrm{mm}$ diameter. Pre-simulation reduces the speed to $110 \mathrm{~mm} / \mathrm{min}$ to protect the tool at the corners, where the instantaneous cutting force is large because the bottom, side and front of the cutter is in contact with the concave workpiece. It increases the feed rate to $3300 \mathrm{~mm} / \mathrm{min}$ to save time in the middle, where the maximum cutting force is small because only the bottom tooth is in contact with the workpiece. The pre-controlled cutting condition is represented by the " $F$ number" and the predicted virtual cutting load by the "(L number)" in the NC data, as shown in Fig. 8 (left). The virtual cutting load is almost identical at the corner and along a straight tool path because the speed is reduced at the corner and increased when in a linear motion.

The material that cannot be removed by a large cutter is machined by a smaller cutter. Fig. 8 (right) shows the re-roughing step, which removes the remaining material from the previous roughing step with a half-size cutter. Pre-simulation reduces the cutting speed to $1500 \mathrm{~mm} / \mathrm{min}$ to protect the tool at the concave corner where the previous larger cutter was unable to cut. It increases the feed rate to $5100 \mathrm{~mm} / \mathrm{min}$ to increase productivity on flat faces where the previous larger cutter has already removed material. The virtual cutting load is 13 at the corners and almost 0 on flat faces. 

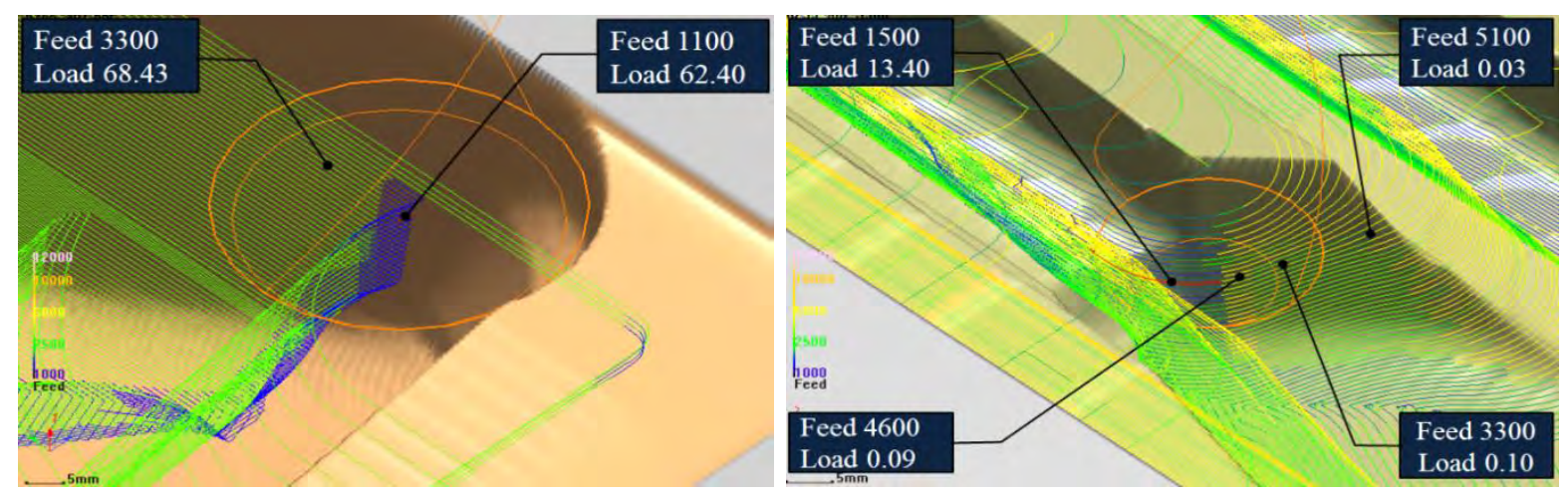

Figure 8: Pre-simulation at the roughing (left) and re-roughing (right) step.

\subsection{Sensorless monitoring mould machining results}

The monitoring module computes the actual load from real-time spindle load data and compares it with the virtual load in $\mathrm{NC}$ data. The time of the actual and virtual load is synchronized using the position data of the CNC controller and X Y Z codes in the NC data. Fig. 9 shows a graph of actual and virtual cutting loads for the mould machining process monitored by the system.

A large volume is removed using a $50-\mathrm{mm}$-diameter rouging cutter at the first rouging step. Pre-simulation controlled cutting conditions and predicted virtual load, which is identified by the L number in the NC data, as shown in Fig. 8 (left). The virtual cutting load is almost identical at the corner and along a straight tool path because the speed is reduced at the corner and increased when in a linear motion. The cutting load varies from 60 to 70 and 82, but the maximum error between the actual and virtual load is approximately 5, as shown in Fig. 9.

Material that cannot be removed by a large roughing cutter is re-machined using a smaller cutter. Pre-simulation reduces the feed rate at concave corners where the large cutter is not able to fit, and increases on flat faces where the previous large cutter has already removed enough material. The virtual load of the $25-\mathrm{mm}$-diameter insert cutter is 13 at the corner and almost 0 on flat faces, as shown in Fig. 8 (right). The actual and virtual cutting load of the reroughing process is shown in Fig. 10. The average peak load is approximately 15 and the maximum error between the actual load and virtual load is approximately 1.8 .

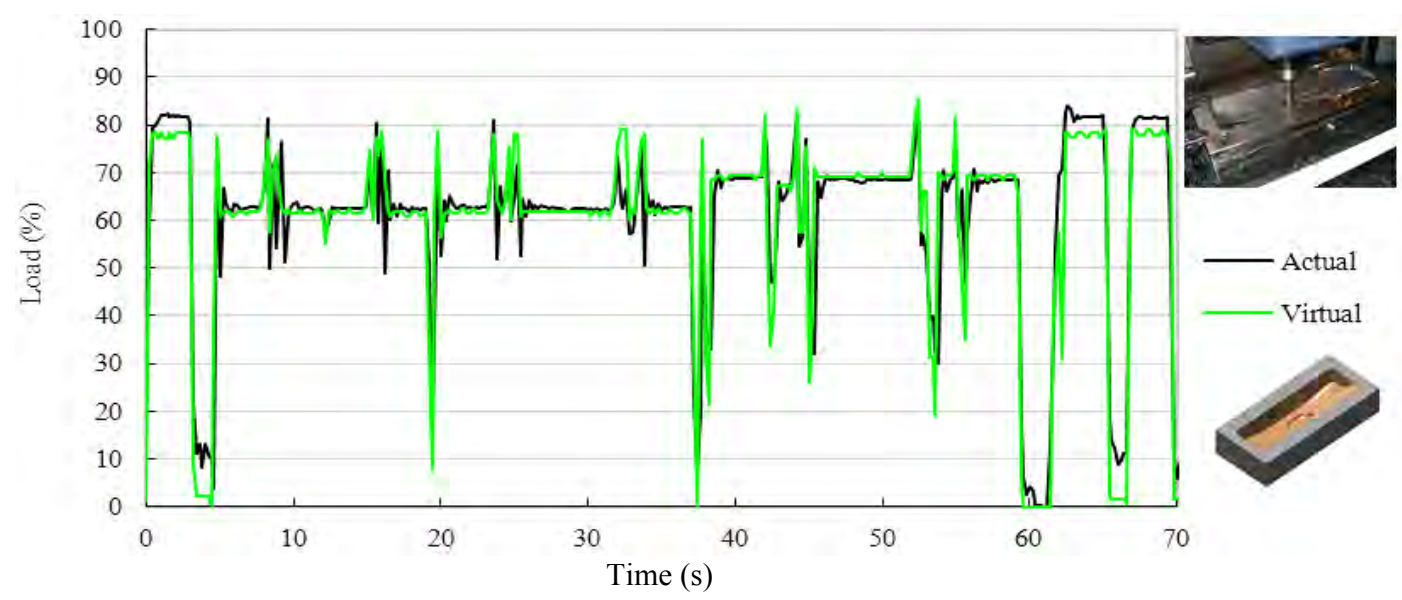

Figure 9: Roughing by a $\Phi 50-\mathrm{mm}$ cutter.

A narrow groove and corner that the large roughing cutter cannot access is pencilmachined using a cutter smaller than the width of the shape. Fig. 11 shows the cutting load when an insert tool with a 16-mm-diameter removes the material remaining from the previous 
step. The peak load is approximately 10 and the maximum error between the actual and virtual load is approximately 2 .

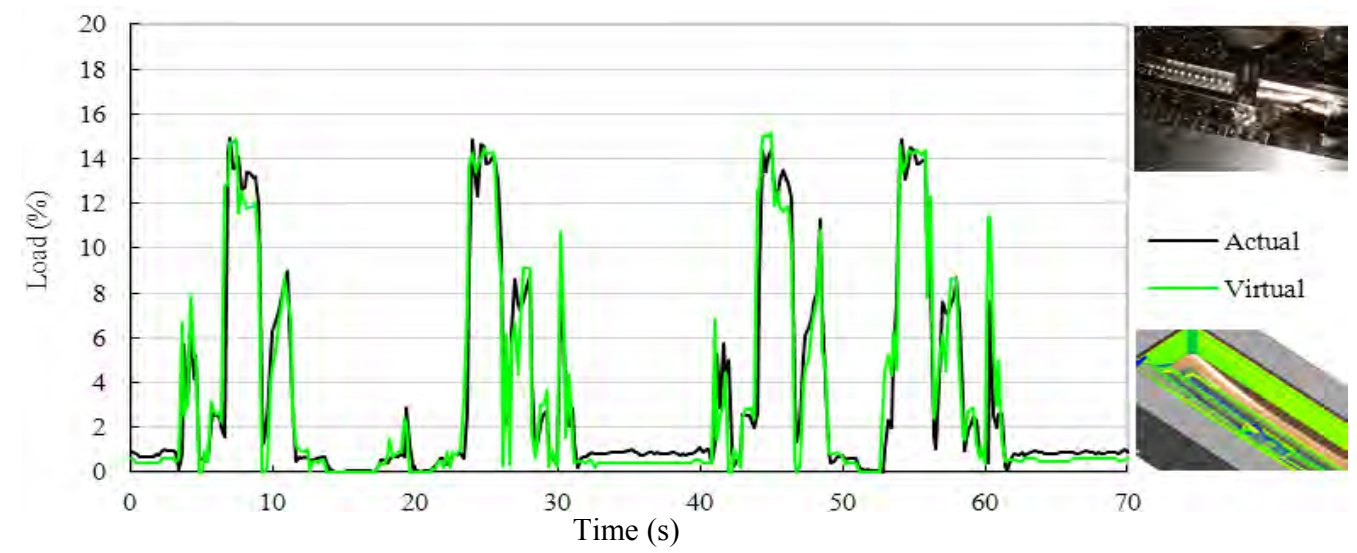

Figure 10: Re-roughing by a $\Phi 25-\mathrm{mm}$ cutter.

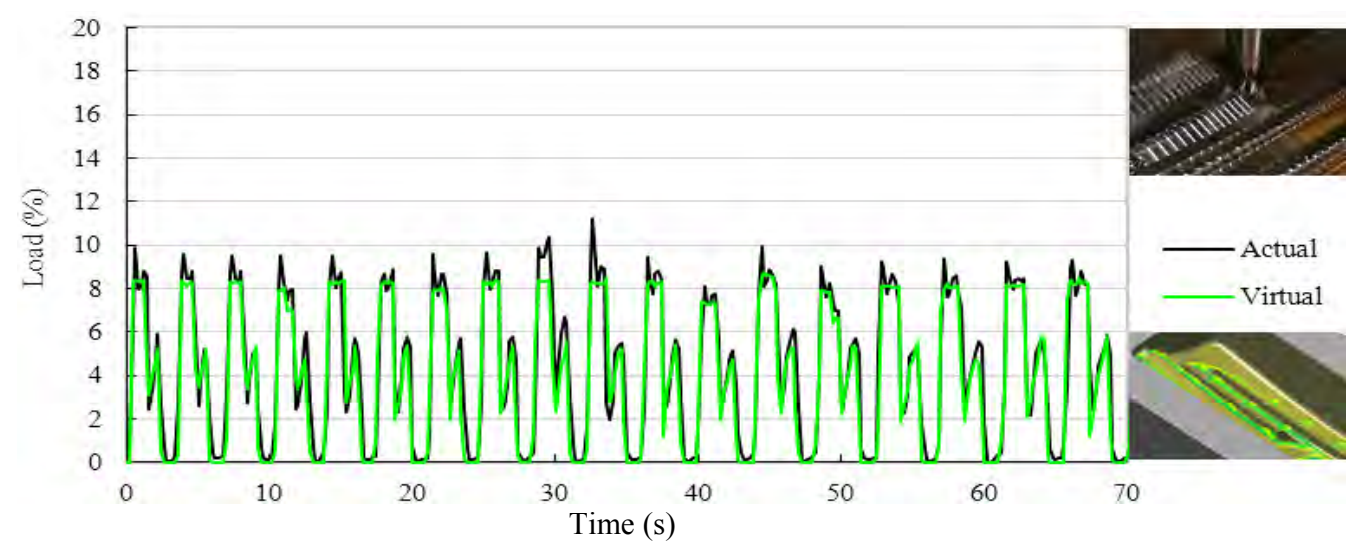

Figure 11: Penciling by a $\Phi 16-\mathrm{mm}$ rounded end mill.

The finishing tool is unable to cut corners with a radius smaller than the finishing tool. The corner is machined by the smallest tool of this process. The re-machining second pick load using a small tool with a diameter of $3 \mathrm{~mm}$ is approximately 1.8 and the maximum error between the actual and virtual load is approximately 0.5 , as shown in Fig. 12 . The tiny cutting tool, which can be easily broken, also outputs load data, with which the system can detect a broken tool incident during the process.

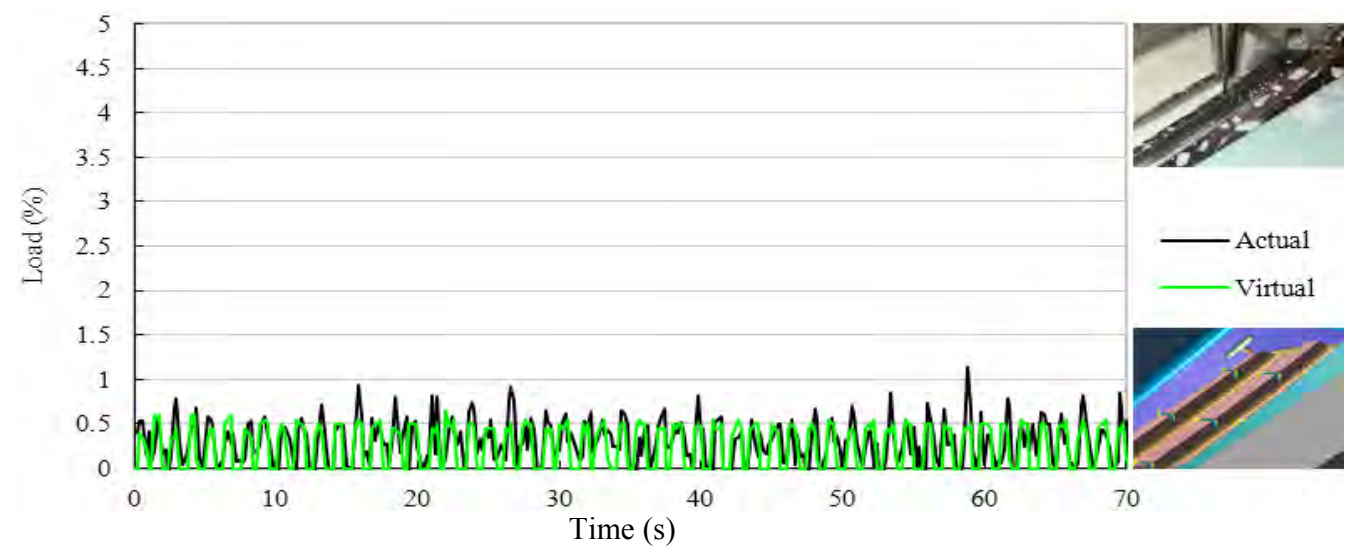

Figure 12: Re-machining by a $\Phi 3-\mathrm{mm}$ ball end mill.

The mould machining experimental results show that the load pattern is the same and the maximum difference between the virtual and actual load is $6 \%$ during the roughing stage, 
$12 \%$ during the re-roughing stage, and $20 \%$ during the pencil-machining process. The experiment proved that the model can be used to monitor roughing, re-roughing, semifinishing and pencil-machining, which showed the same actual and virtual load patterns.

In the experiment, the virtual load estimated by the cutting simulation was similar to the actual spindle load, if the cutting state was normal. In other words, it can be considered that there is a problem with the machine or cutting tool if the actual load is different from the virtual load.

The total machining time for the pre-controlled NC data was 39 hours, which is approximately $30 \%$ less than the predicted time for the original data using a constant feed rate, because pre-simulation increased the feed rate when a tool moves onto a flat surface that has already had material removed during the previous step. Machining was stable because pre-simulation reduced the feed rate at concave corners to limit the maximum cutting force. The automotive grill cavity was machined unmanned for 34 hours after the roughing process, because pre-simulation had controlled the cutting conditions to limit the maximum cutting force, and sensorless monitoring would have stopped the machine tool and sent a message to a smart phone if the cutting state was different to the pre-simulated data.

\subsection{Integration in an Open CNC}

An open $\mathrm{CNC}$ is configured to a human-machine interface and $\mathrm{NC}$ control units. If the operating system of the human-machine interface is a Windows operating system, software developed by Visual $\mathrm{C}++$ and Ethernet communication can be installed in the open CNC. The developed pre-simulation and sensorless monitoring software were integrated in the Windows operating system of Fanuc 30i and exhibited at SIMTOS 2014, as shown in Fig. 13. The smart $\mathrm{CNC}$ pre-simulates machining and monitors the process. Rapid motion collision data are replaced by safe height data, and machining is more stabilized and faster as a result of feed rate pre-control. An automatic tool setter on the machine tool measures tool size before cutting starts, and checks for tool wear or breakage after machining. Unpredicted collision error and tool wear is monitored using real-time data and predicted reference data. This application is not limited to the mould industry, but could also be used in 5-axis machining of turbine engines and aircraft parts, as shown in Fig. 13 [27].

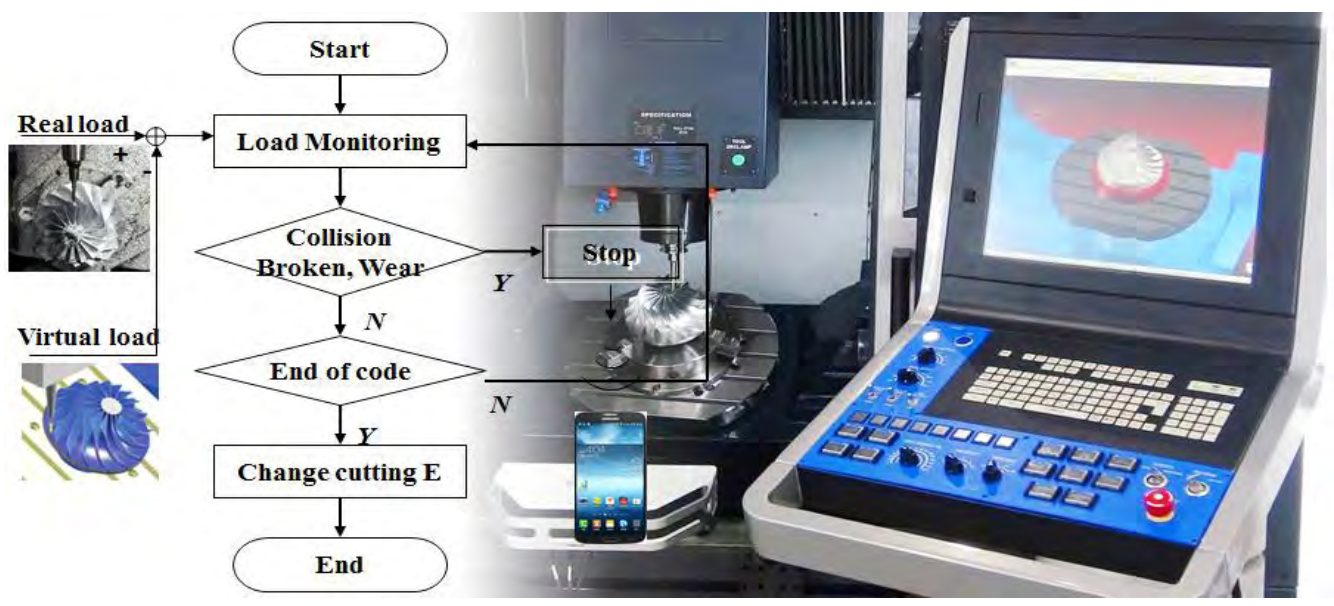

Figure 13: Pre-simulation and sensorless monitoring integrated in an open CNC.

\section{CONCLUSION}

Pre-simulation and sensorless monitoring technology that recognise the machining status and determine better conditions were developed and integrated in an open CNC. Pre-simulation increases the rapid height to prevent collisions at rapid motion, and regulates feed rate to 
stabilize the process and reduce time. It was evaluated by machining a SM45C block using a $10-\mathrm{mm}$-diameter ball end mill, and the active feed rate reduced the machining time by up to $36 \%$ without increasing instantaneous maximum cutting forces compared to the protective cutting conditions, considering the worst case. The simulation technology was commercialized and has been verified by thousands of mould makers.

It inserted virtual loads, the average of element forces, at every line in the $\mathrm{NC}$ data during the monitoring step. The actual cutting load is computed by removing the friction load and acceleration load from the spindle load data. Since the acceleration load is too large to be accurately compensated, the system detected the initial friction load a short time after the spindle change, and the actual cutting load was calculated by compensating for slow friction load changes on the cutting process. The monitoring step synchronised the time of the actual and virtual load data using tool position data, and it detected over cut collisions and tool wear during the process by comparing the two data.

The system machined a cavity of an automotive grill mould for 34 hours without operator supervision after a 5-hour roughing process that required changing inserts frequently. Presimulation controlled cutting conditions to achieve process stability, and monitoring would have stopped the machine tool if real-time data were different to the virtual load. The smart machining system was able to be integrated in Fanuc 30i, because it obtains real-time status data and controls process conditions using the local Ethernet without sensors.

\section{ACKNOWLEDGEMENT}

Thanks to Kim Du-Jin of NCB Co. Ltd., who has supported the smart mould machining system research for 10 years. The pre-simulation software NCBrain has been used by thousands of mould makers, and the smart machining system integrated in Fanuc 30i was exhibited at SIMTOS 2014.

\section{REFERENCES}

[1] Hadzistevic, M.; Matin, I.; Hodolic, J.; Vukelic, D.; Vukmirovic, S.; Godec, D.; Nedic, B. (2014). Rule base reasoning in the knowledge-based mould design system, Technical Gazette, Vol. 21, No. 5, 1143-1148

[2] Prickett, P. W.; Johns, C. (1999). An overview of approaches to end milling tool monitoring, International Journal of Machine Tools and Manufacture, Vol. 39, No. 1, 105-122, doi:10.1016/S0890-6955(98)00020-0

[3] Cerce, L.; Pusavec, F.; Kopac, J. (2015). A new approach to spatial tool wear analysis and monitoring, Strojniski vestnik - Journal of Mechanical Engineering, Vol. 61, No. 9, 489-497, doi:10.5545/sv-jme.2015.2512

[4] Nouri, M.; Fussell, B. K.; Ziniti, B. L.; Linder, E. (2015). Real-time tool wear monitoring in milling using a cutting condition independent method, International Journal of Machine Tools and Manufacture, Vol. 89, 1-13, doi:10.1016/j.ijmachtools.2014.10.011

[5] Altintas, Y.; Yellowley, I. (1989). In-process detection of tool failure in milling using cutting force models, Journal of Engineering for Industry, Vol. 111, No. 2, 149-157, doi: $10.1115 / 1.3188744$

[6] Tarn, J. H.; Tomizuka, M. (1989). On-line monitoring of tool and cutting conditions in milling, Journal of Engineering for Industry, Vol. 111, No. 3, 206-212, doi:10.1115/1.3188751

[7] Kim, S.; Klamecki, B. E. (1997). Milling cutter wear monitoring using spindle shaft vibration, Journal of Manufacturing Science and Engineering, Vol. 119, No. 1, 118-119, doi:10.1115/ 1.2836548

[8] Tlusty, J.; Tarng, Y. S. (1988). Sensing cutter breakage in milling, CIRP Annals - Manufacturing Technology, Vol. 37, No. 1, 45-51, doi:10.1016/S0007-8506(07)61583-2

[9] Altintas, Y. (1992). Prediction of cutting forces and tool breakage in milling from feed drive current measurements, Journal of Engineering for Industry, Vol. 114, No. 4, 386-392, doi: $\underline{10.1115 / 1.2900688}$ 
[10] Lee, J. M.; Choi, D. K.; Kim, J.; Chu, C. N. (1995). Real time tool breakage monitoring for NC milling process, CIRP Annals - Manufacturing Technology, Vol. 44, No. 1, 59-62, doi: $10.1016 / \mathrm{S} 0007-8506(07) 62275-6$

[11] Kim, T.-Y.; Kim, J.-W. (1996). Adaptive cutting force control for a machining center by using indirect cutting force measurements, International Journal of Machine Tools and Manufacture, Vol. 36, No. 8, 925-937, doi:10.1016/0890-6955(96)00097-1

[12] Jesús, R.-T. R.; Gilberto, H.-R.; Iván, T.-V.; Carlos, J.-C. J. (2003). Driver current analysis for sensorless tool breakage monitoring of CNC milling machines, International Journal of Machine Tools and Manufacture, Vol. 43, No. 15, 1529-1534, doi:10.1016/j.ijmachtools.2003.08.004

[13] Ulsoy, A. G.; Koren, Y.; Rasmussen, F. (1983). Principal developments in the adaptive control of machine tools, Journal of Dynamic Systems, Measurement, and Control, Vol. 105, No. 2, $107-$ 112, doi: $10.1115 / 1.3149640$

[14] Yellowley, I. (1985). Observations on the mean values of forces, torque and specific power in the peripheral milling process, International Journal of Machine Tool Design and Research, Vol. 25, No. 4, 337-346, doi:10.1016/0020-7357(85)90034-4

[15] Yang, M.-Y., Lee, T.-M. (2002). Hybrid adaptive control based on the characteristics of CNC end milling, International Journal of Machine Tools and Manufacture, Vol. 42, No. 4, 489-499, doi:10.1016/S0890-6955(01)00138-9

[16] Deyuan, Z.; Yuntai, H.; Dingchang, C. (1995). On-line detection of tool breakages using telemetering of cutting forces in milling, International Journal of Machine Tools and Manufacture, Vol. 35, No. 1, 19-27, doi:10.1016/0890-6955(95)80006-9

[17] Altintas, Y.; Kersting, P.; Biermann, D.; Budak, E.; Denkena, B.; Lazoglu, I. (2014). Virtual process systems for part machining operations, CIRP Annals - Manufacturing Technology, Vol. 63, No. 2, 585-605, doi:10.1016/j.cirp.2014.05.007

[18] Chaari, R.; Abdennadher, M.; Luati, J.; Haddar, M. (2011). Modelling of the 3D machining geometric defects accounting for workpiece vibratory behaviour, International Journal of Simulation Modelling, Vol. 10, No. 2, 66-77, doi:10.2507/IJSIMM10(2)2.173

[19] Kim, S.-J. (2007). Short and safe tool setting by safe space in NC machining, International Journal of Advanced Manufacturing Technology, Vol. 33, No. 9-10, 1017-1023, doi:10.1007/s00170-006-0526-2

[20] Zuperl, U.; Cus, F. (2015). Simulation and visual control of chip size for constant surface roughness, International Journal of Simulation Modelling, Vol. 14, No. 3, 392-403, doi:10.2507/IJSIMM14(3)2.282

[21] Fussell, B. K.; Jerard, R. B.; Hemmett, J. G. (2000). Robust feedrate selection for 3-axis NC machining using discrete models, Journal of Manufacturing Science and Engineering, Vol. 123, No. 2, 214-224, doi:10.1115/1.1365398

[22] Fussell, B. K.; Jerard, R. B.; Hemmett, J. G. (2003). Modeling of cutting geometry and forces for 5-axis sculptured surface machining, Computer-Aided Design, Vol. 35, No. 4, 333-346, doi:10.1016/S0010-4485(02)00055-6

[23] Altintas, Y.; Spence, A.; Tlusty, J. (1991). End milling force algorithms for CAD systems, CIRP Annals-Manufacturing Technology, Vol. 40, No. 1, 31-34, doi:10.1016/S0007-8506(07)61927-1

[24] Yun, W.-S.; Cho, D.-W. (2001). Accurate 3-D cutting force prediction using cutting condition independent coefficients in end milling, International Journal of Machine Tools and Manufacture, Vol. 41, No. 4, 463-478, doi:10.1016/S0890-6955(00)00097-3

[25] Weinert, K.; Enselmann, A.; Friedhoff, J. (1997). Milling simulation for process optimization in the field of die and mould manufacturing, CIRP Annals - Manufacturing Technology, Vol. 46, No. 1, 325-328, doi:10.1016/S0007-8506(07)60835-X

[26] Álvares, A. J.; Ferreira, J. C. E. (2006). WebTurning: Teleoperation of a CNC turning center through the Internet, Journal of Materials Processing Technology, Vol. 179, No. 1-3, 251-259, doi:10.1016/j.jmatprotec.2006.03.096

[27] NCB Co. Ltd. NCBrain - Mould Machining Simulation \& Optimization Software, from http://www.ncbrain.com/, accessed on 14-11-2015 